\title{
Morphometry of Parietal Foramen in Skulls of Telangana Population
}

\author{
Dr. T. Sumalatha ${ }^{1}$, Dr. V. Sailaja ${ }^{2 *}$, Dr. S. Deepthi ${ }^{3}$, Dr. Mounica Katukuri ${ }^{4}$
}

\author{
${ }^{1}$ Associate professor, Department of Anatomy, Government Medical College, Mahabubnagar, Telangana, India \\ ${ }^{2}$ Assistant Professor, Department of Anatomy, Gandhi Medical College, Secunderabad, Telangana, India \\ ${ }^{3}$ Assistant Professor, Department of Anatomy, Government Medical College, Mahabubnagar, Telangana, India \\ ${ }^{4}$ Post Graduate 2nd year, Gandhi Medical College, Secunderabad, Telangana, India
}

\author{
DOI: $10.36348 /$ sijap.2020.v03i10.001 \\ | Received: 06.10.2020 | Accepted: 14.10.2020 | Published: 18.10.2020 \\ *Corresponding author: Dr. V. Sailaja
}

\section{Abstract}

\begin{abstract}
Aims \& Objectives: To study the prevalence, number, location and variations of parietal foramen in human skulls and correlate with the clinical significance if any. Material and Methods: A total of 45 skulls with 90 parietal bones were studied in the Department of Anatomy Govt medical college Mahabubnagar from osteology specimens in the academic year 2018-2019.Various parameters like unilateral or bilateral occurance or total absence of the parietal foramen, their location in relation to sagittal suture and lambda, their shape have been observed using appropriate tools and the findings have been tabulate. Observation \& Conclusions: Out of total 45 skulls there were 64 parietal foramina in 90 parietal bones, with foramina only on right side in 10 skulls, only on left side in 7 skulls, bilaterally present in 23 skulls, total absence in 4 skulls and 1 foramen located in the sagittal suture. Right foramen is at a mean distance of $0.58+/-3.6 \mathrm{~mm}$ from sagittal suture \& left is at $0.54+/-3.7 \mathrm{~mm}$ from sagittal suture. Only 1 foramen was more close to lambda, rest (63) are at the junction of anterior $2 / 3^{\text {rd }} \&$ posterior $1 / 3^{\text {rd }}$ of sagittal suture. Shape of 18 foramina were Circular, 10 were Slit like and the rest 36 were Oval.

Keywords: Parietal foramen, sagittal suture, lambda.

Copyright () 2020 The Author(s): This is an open-access article distributed under the terms of the Creative Commons Attribution 4.0 International License (CC BY-NC 4.0) which permits unrestricted use, distribution, and reproduction in any medium for non-commercial use provided the original author and source are credited.
\end{abstract}

\section{INTRODUCTION}

Located on either side of Sagittal suture at the junction of posterior one third and middle one third of the suture are a pair of parietal foramina which are emissary foramina. The emissary foramen allow the passage of emissary veins the purpose of which is to connect intracranial venous sinuses with extracranial veins of the scalp [1]. They drain the venous blood from cephalic structures and act as output veins of neurocranium. They become an important source of drainage of blood in cases of increased intracranial pressure [2]. Clinical significance of parietal foramen is that they allow the passage of emissary veins that connect scalp veins with that of superior sagittal sinus, through which they not only drain the scalp but also spread the infection to sinuses of the duramater [3]. Even though these emissary veins are valved, they allow the blood flow in both the directions.

All the cranial foramina which transmit an emissary vein are not considered as the emissary foramina. In the routine usage, the term is applied to the parietal foramen, mastoid foramen, condylar foramen and the sphenoidal emissary foramen. It can also include foramen in the occipital bone and the foramen caecum. The emissary foramina are commonly described as the channel for the emissary vein [4].

There are numerous foramina in the skull through which not only the emissary veins but also other vascular and vital neural structures course through. A thourough knowledge of these foramens is essential not only for understanding the regional anatomy but also to identify and distinguish normal from abnormal appearances.

Variations of these foramen have been of interest for neuroanatomists especially neurosurgeons considering the clinical consequences that these can cause. As these anatomical variations are mostly rare or occasional, most of them are tend to be neglected by the clinicians. Complications can occur during clinical interventions due to poor interpretation of such variations. This can be the reason for various procedural failures performed around the foramen near those areas causing damage to vital vascular and neural structures [5]. 
Thus there is a need for a detailed knowledge of three dimensional topographic anatomy of skull structures and their anomalies for performing a safe treatment, for students and health areas who work on the Head and neck [6]. The present study is carried out considering the clinical significance of variations in position, number, size $\&$ shape of parietal foramen.

\section{MATERIALS AND METHODS}

There were 45 adult human dried crania in the present study with a total of 90 parietal bones. These crania were present at the Osteology department in the Department of Anatomy, Government medical college Mahabubnagar, \& were examined for the presence, dexterity, number, shape and topography of the emissary foramen. The foramina were macroscopically observed for the shape and patency by using a magnifying lens and a needle probed into each foramen. The morphometric data of the present study like the distance of the foramen from sagittal suture \& lambda was performed by using a measuring scale and a divider. The data is presented as mean $\pm \mathrm{SD}$ and were tabulated.

\section{RESULTS \\ Occurance of Foramen}

The emissary foramen was observed in 63 parietal bones $(70 \%)$ out of 90 parietal bones in the present study. It was located at the junction between the middle $1 / 3$ and posterior $1 / 3$ region of the parietal bone except one foramen which is located more close to Lambda. It was bilaterally present (Fig-1A) in 23 skulls $(51.1 \%)$ and unilaterally present (Fig-1B) in 18 skulls (40\%). The bilateral absence (Fig-1C) of parietal emissary foramen was seen in 4 skulls $(8.89 \%)$. The side wise comparison of the frequency of the number of emissary foramen in the parietal bones of the present study is shown in Table- 1 .

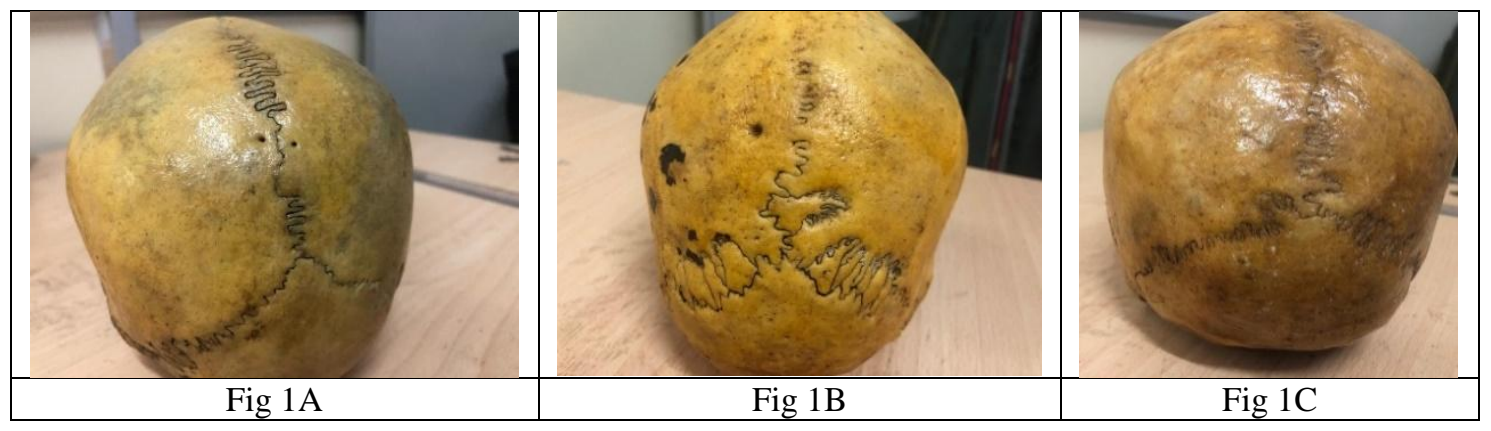

Table-1: Sidewise comparison of the number of foramen in the parietal bones $(n=63)$

\begin{tabular}{|l|l|l|}
\hline Parietal bone & Right sided $(\mathbf{n = 4 5})$ & Left sided $(\mathbf{n = 4 5})$ \\
\hline Single foramen & $33(73.33)$ & $30(66.67)$ \\
\hline Double foramen & $0(0)$ & $0(0)$ \\
\hline Triple foramen & $0(0)$ & $0(0)$ \\
\hline No foramen & $12(26.67)$ & $15(33.33)$ \\
\hline
\end{tabular}

Values are presented as number $(\%)$.

The foramen was solitary in 63 parietal bones (70\%), absent in 27 parietal bones (30\%). The parietal emissary foramina were neither double nor multiple in any of the bones. There is 1 skull in the present study $(2.22 \%)$, which exhibited the parietal foramen over the sagittal suture (Fig-1D).

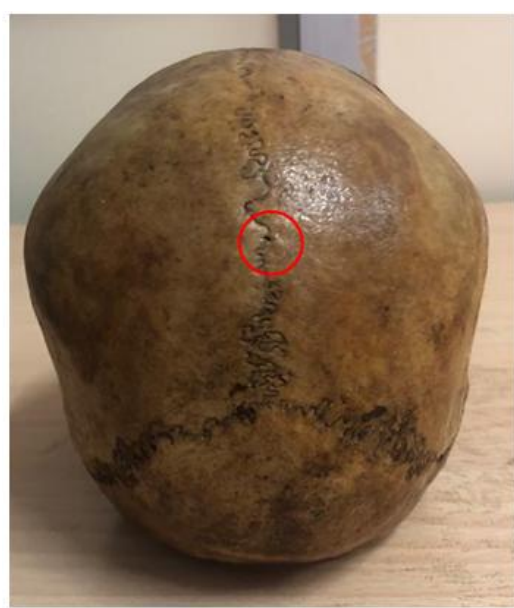

Fig-1D 
Table-2: Comparison of frequency of parietal emissary foramen with previous reports

\begin{tabular}{|l|l|l|l|}
\hline Author & Unilateral foramen & Bilateral foramen & Absent foramen \\
\hline Boyd [4] & 40.5 & 19.9 & 39.6 \\
\hline Yoshioka et al., [7] & 20 & 40 & 40 \\
\hline Muralimanju et al., [8] & 32.7 & 55.2 & 12.1 \\
\hline Present study & 40 & 51.1 & 8.9 \\
\hline
\end{tabular}

\section{Values are presented as percentage Distance of Foramen}

The mean distance of the emissary foramen from the sagittal suture was $5.8 \pm 3.6 \mathrm{~mm}$ and $5.4 \pm 3.7$ $\mathrm{mm}$ on the right and left sides respectively. The distance of the foramen from the sagittal suture ranged from $2 \mathrm{~mm}$ to $19 \mathrm{~mm}$ and $2 \mathrm{~mm}$ to $11 \mathrm{~mm}$ on the right and left sides respectively. The findings have been tabulated in Table-3.

Table-3: Sidewise comparison of range of distance of the foramen from the sagittal suture

\begin{tabular}{|l|l|l|}
\hline Distance $\mathbf{( m m})$ & Right side & Left side \\
\hline $0-2$ & 3 & 3 \\
\hline $2.1-4$ & 5 & 5 \\
\hline $4.1-6$ & 8 & 10 \\
\hline $6.1-8$ & 14 & 9 \\
\hline $8.1-10$ & 6 & 7 \\
\hline $10.1-12$ & 1 & 4 \\
\hline $12.1-14$ & 1 & 0 \\
\hline $14.1-16$ & 0 & 0 \\
\hline $16.1-18$ & 0 & 0 \\
\hline $18.1-20$ & 1 & 0 \\
\hline
\end{tabular}

\section{Shape of the foramen}

The shapes of the foramina were studied \& most of them were oval (36) few were circular (18) \& some were slit like (10).

\section{DISCUSSION}

The parietal foramina are usually bilaterally located one on either side of sagittal suture at the level of obelion, but may appear unilateral or may be absent $[3,9]$. Incidence of presence of foramina ranges from 50 to $80 \%$ in different groups and also show variations in their shape, size, number \& location [7, 10]. Boyd has observed that parietal foramen are rarely present in lower animals except in Simians, which stand next to man in zoological scale, and it is always single. It is most frequent in Gorilla, being present in $33 \%$ of cases while in man it is present in $60 \%$ cases [4].

Parietal foramen in new borns is located $2 \mathrm{~cm}$ anterior to lambda, while in adults it is located $2-3 \mathrm{~cm}$ anterior to external occipital protuberance or posterior $1 / 3$ rd of parietal bone [11] or an average distance of $83 \mathrm{~mm}$ from the Inion [7]. In few studies the parietal foramen is reported as being located in the posterior one fifth [12] .In our study only 1 foramen was more close to lambda, rest are at the junction of anterior $2 / 3^{\text {rd }} \&$ posterior $1 / 3^{\text {rd }}$ of sagittal suture.

The curved distance from the Lambda to the foramen was measured, which resulted in an average distance and range of $3.8 \mathrm{~cm}$ and $2-5 \mathrm{~cm}$, respectively by Mann et al.,
We have noted the distance of foramen both in relation to sagittal suture and lambda. The mean distance of the emissary foramen from the sagittal suture was $5.8 \pm 3.6 \mathrm{~mm}$ and $5.4 \pm 3.7 \mathrm{~mm}$ on the right and left sides respectively. These findings are close to those done by Manjumurali et al., where the mean distance of the emissary foramen from the sagittal suture was $6.7 \pm 2.9 \mathrm{~mm}$ and $6.8 \pm 2.8 \mathrm{~mm}$ on the right and left sides respectively.

The distance of the foramen from the sagittal suture ranged from $2 \mathrm{~mm}$ to $19 \mathrm{~mm}$ and $2 \mathrm{~mm}$ to 11 $\mathrm{mm}$ on the right and left sides respectively in the present study, while in the studies done by Manjumurali et al., the distance of the foramen from the sagittal suture ranged from $0.5 \mathrm{~mm}$ to $13 \mathrm{~mm}$ and $1 \mathrm{~mm}$ to 15 $\mathrm{mm}$ on the right and left sides respectively which are nearer to the present study readings.

The distance of the parietal emissary foramen from the sagittal suture is clinically essential. During the surgical procedures done by neurosurgeons this knowledge is important as the emissary veins may be ruptured and cause spontaneous bleeding.

A sexual dimorphism was also noted, with average size being twice major in female skulls than in males [10]. Boyd have reported that the average size of this foramen is less than $0.5 \mathrm{~mm}$ and a size larger than $1.5 \mathrm{~mm}$ is rare. 
Parietal foramen may also occur in different forms like circular, oval or fissure [13-15]. In our study most of them were oval $(56.3 \%)$ few were circular $(28.1 \%) \&$ some were slit like $(15.6 \%)$. The different occurences of parietal foramen are due to differences in ossification process of anterior fonticulus. A few studies found a small transverse parietal suture on one or both sided of this area [7].

The parietal bone development begins in eighth week of intrauterine week from a single intramembranous center near the eminence, and radiates outward in a sunburst pattern $[12,16,17]$

The four sides of this approximately square shaped bone, which forms the sides and roof of the skull, join the temporal and sphenoid bones inferiorly at the squamosal suture, the frontal bone anteriorly along the coronal suture, the occipital bone posteriorly along the lambdoidal suture, and the opposing parietal bone superiorly at the sagittal suture [18].

The prevalence of foramen as per our studies is in close comparison to the data of Boyd [4] studies and those of Muralimanju et al., [8]. The unilateral parietal foramen is seen more common on the right side than the left $(20.7 \%: 15.2 \%)$ as per studies done by Boyd. Majority of foramen in our study were oval in shape. The median foramen over the sagittal suture was present in $5.9 \%$ cases of Boyd study specimens. This is almost similar to the present study as we observed the median foramen over the sagittal suture in $2.22 \%$ of cases. In the present study we observed no accessory parietal emissary foramina compared to Boyd where accessory parietal foramina were observed in $2 \%-5 \%$ of cases. The reason may be due to the racial and geographical variations.

As mentioned by Piersol [19], an author of a text book, emissary veins are responsible for half the frequency of the injuries and diseases of the scalp. There are cases where parietal emissary foramina may be absent and perhaps be the reason of severe scalp sepsis with no intracranial complications [4]. Thus emissary foramina identification is of utmost importance for understanding the regional vessels and to distinguish them from the abnormal structures [20]. The present study has provided additional information about the number, location and shape of the parietal foramen but has certain limitations like the racial and sexual differences which are yet to be studied.

The present study could even provide the distance of the parietal foramen from the sagittal suture, the knowledge of which might be of use to the neurosurgeons and radiologists in their clinical consideration. It was observed that the most of the foramina were located about $4-8 \mathrm{~mm}$ away from the sagittal suture.

\section{CONCLUSION}

Considering the significance of the position, shape, number \& distance of parietal emissary foramina from the sagittal suture, the present study has been carried out. In the present work the authors have studied in 45 dried skulls, the variations in the occurance of parietal foramen where the foramen were absent in 4 skulls $(8.89 \%)$, bilaterally present in 23 skulls $(51.1 \%)$ and unilaterally present in 18 skulls $(40 \%)$ more on right side $(73.33 \%)$ than on the left $(66.67 \%)$ with one foramen observed on the sagittal suture. We could find the position of the foramen in majority is at the junction of anterior $2 / 3^{\text {rd }} \&$ posterior $1 / 3^{\text {rd }}$ of sagittal suture, most of the foramen are bilaterally located, oval in shape \& at an average distance of $4-8 \mathrm{~mm}$ away from sagittal suture. These findings are to be further refined by considering the limitations of the present study like small sample size, racial, age \& gender specifications which we shall be considering in our further studies.

\section{REFERENCES}

1. Standring, S. (2005). Gray's anatomy. 39th edition. Elsevier Churchill Livingstone, Edinburgh.

2. Reis, C., Deshmukh, V., Zabramski, J. M., Crusius, M., Desmuskh, P., Spetzler, R. E., \& Preul, M. C. (2007). Anatomy of the mastoid emissary vein and venous system of the posterior neck region: neurosurgicalimplications. Neurosurg, 61:ONS193-ONS201.

3. Sicher, H., \& DuBrul, E. L. (1977). Oral anatomy. 6th ed. Rio de Janeiro: Guanabara Koogan.

4. Boyd, G. I. (1930). The emissary foramina of the cranium in man and the anthropoids. J Anat; 65:108-21.

5. Gozil, R., Kadioglu, D., \& Calguner, E. (1995). Occipital emissary foramen in skulls from Central Anatolia. Act Anat, 153: 325-6.

6. Keskil, S., Gozil, R., \& Calguner, E. (2003). Common surgical pitfalls in the skull. Surg Neurol, 59(3): 228-31.

7. Yoshioka, N., Rhoton Jr, A. L., \& Abe, H. (2006). Scalp to meningeal arterial anastomosis in the parietal foramen. Operative Neurosurgery, 58(suppl_1), ONS-123.

8. Murlimanju, B. V., Saralaya, V. V., Somesh, M. S., Prabhu, L. V., Krishnamurthy, A., Chettiar, G. K., \& Pai, M. M. (2015). Morphology and topography of the parietal emissary foramina in South Indians: an anatomical study. Anatomy \& cell biology, 48(4), 292-298.

9. Le Double, A. F. (1903). Traité des variations des os du crâne de l'homme et de leur signification au point de vue de l'anthropologie zoologique. Vigot.

10. Wysocki, J., Reymond, J., Skarzynski, H., \& Wróbel, B. (2006). The size of selected human skull foramina in relation to skull capacity. Folia Morphol, 66(4): 301-08. 
11. Currarino, G. (1976). Normal variants and congenital anomalies in the region of the obelion. Am J Roentgenol, 127(3):487-94.

12. Topinard, P. (1878). Anthropology. London, Chapman and Hall.

13. O'Rahilly, R., \& Twohig, M. J. (1952). Foramina parietalia permagna. Am J Roentgenol, 67(4):55161.

14. Mann, R. W. (1990). Enlarged parietal foramina and craniosynostosis in an American Indian child. Am J Roentgenol, 154(3):658.

15. Keats, T. E. (1992). Atlas of normal roentgen variants that may simulate disease. 5th edition. St. Louis, Mosby Year Book, 1992.

16. Hoheisel, W. F. (1930). An anomalous Indian occiput. Anat Rec, 45(2):129-35.
17. Steele, G. D., \& Bramblett, C. A. (1988). The anatomy and biology of the human skeleton. Texas, Texas A \& M University Press.

18. Gray, H. (1910). Anatomy: descriptive and applied (ed. Spitzka EA), 18. Ed. Philadelphia, PA, Lea \& Febiger.

19. Piersol. (1919). Text-Book Anat. 869, 870, 876.

20. Freire, A. R., Rossi, A. C., de Oliveira, V. C. S., Prado, F. B., Caria, P. F., \& Botacin, P. R. (2013). Emissary Foramens Of The Human Skull: Anatomical Characteristics And Its Relations With Clinical Neurosurgery [forámenes Emisarios Del Cráneo Humano: Características Anatómicas Y Sus Relaciones Con La Neurocirugía Clínica]. International Journal of Morphology. 